\title{
Um estudo sobre a itinerância como estratégia de cuidado no contexto das políticas públicas de saúde no Brasil
}

| ${ }^{1}$ Ruben Artur Lemke, ${ }^{2}$ Rosane Azevedo Neves da Silva |

Resumo: O presente artigo tem como objetivo problematizar a itinerância como um modo de operacionalizar o cuidado no território. Com a emergência do Sistema Único de Saúde, a noção de território se tornou um princípio organizador dos processos de trabalho nas políticas de Atenção Básica e Saúde Mental. No campo delicado de articulação entre essas políticas, as práticas itinerantes passaram a ter uma importância estratégica na desinstitucionalização das práticas e na construção da integralidade do cuidado. Tomamos a desinstitucionalização e a integralidade como os operadores conceituais que marcam a diferença que as reformas Psiquiátrica e Sanitária pretendem imprimir nas práticas de cuidado. Advertimos que, ao ingressar numa postura de busca ativa no território de vida dos usuários, as práticas itinerantes se inserem num campo de tensões, no qual podem tanto ser convocadas a funcionar como uma peça do aparelho de Estado no controle da população, como se situar num lugar estratégico para a construção de um cuidado contextualizado aos modos de vida dos usuários. Defendemos que é possível resistir ao mandato social de controle e construir uma ética do cuidado com a itinerância ao explorar a potência política do movimento e transformar o território dos usuários num laboratório de invenção de vida.
1 Psicólogo; mestre em Psicologia Social. Professor do curso de Psicologia da Universidade AnhangueraUniderp. Endereço eletrônico: ruben.lemke@uniderp.edu.br

2 Professora do Programa de Pós-Graduação em Psicologia Social e Institucional (UFRGS). Endereço eletrônico: rosane. neves@ufrgs.br 


\section{Introdução}

No campo das políticas públicas, tem sido recorrente a utilização da estratégia da itinerância para operacionalizar objetivos e desenvolver projetos, principalmente nas áreas da saúde e da assistência social. Diversas tecnologias de cuidado têm sido implementadas utilizando o deslocamento nos territórios de vida dos usuários tanto com o objetivo de cobrir uma maior extensão territorial, para - numa lógica de busca ativa - alcançar grupos populacionais vulneráveis, quanto para atender às demandas de usuários que não se adaptam aos equipamentos tradicionais de atenção. Podemos citar como exemplo desses grupos populacionais os moradores de rua, as comunidades indígenas de costumes nômades, as pessoas que usam drogas e que não se adaptam a protocolos clínicos que exigem a abstinência, e os usuários refratários ao atendimento nos serviços de Saúde Mental.

Essas tecnologias de cuidado, embora possuam diferenças específicas quanto aos seus objetivos, amplitude de ações e população alvo - diferenças referentes às políticas públicas às quais se vinculam -, guardam em comum algumas características formais que as atravessam e colocam em questão a ética do cuidado no trabalho junto aos espaços de existência dos usuários.

A prática dos trabalhadores itinerantes se situa num campo de tensão em que pode tanto ser convocada a atuar como um artefato a serviço da Razão de Estado no controle e normalização de populações e no silenciamento de diferenças incômodas, como estar numa posição estratégica para a construção de um cuidado contextualizado nos modos de vida dos usuários. A entrada que esses trabalhadores realizam no cotidiano de vida das pessoas, nos seus domicílios, nas suas famílias e nas suas comunidades pode somar forças a qualquer um destes polos: seja a capilarização de um controle mais acurado e minucioso ou a contextualização de um cuidado que atue pela promoção de saúde, no sentido da melhoria da qualidade de vida das pessoas e do incremento de ganhos de autonomia dos usuários.

Com a implantação do Sistema Único de Saúde (SUS), cujas bases se fundamentam nos princípios de universalidade e equidade - que pressupõe a criação de estratégias que promovam o acesso à saúde para as populações mais vulneráveis - e de integralidade - que afirma que essas estratégias levem em consideração a complexidade dos territórios existenciais dos usuários -, as tecnologias de trabalho itinerante passaram a ter uma relevância estratégica especial. 
A universalidade, que torna a saúde um direito social de todos e dever do Estado em provê-la mediante a criação de políticas públicas, exige estratégias para aumentar a cobertura da atenção. Já a equidade, princípio político de justiça social, requer que as ações de saúde sejam intensificadas nas populações mais vulneráveis, que estão em maior sofrimento, com o objetivo de aplacar suas vulnerabilidades sociais. Esses dois princípios, juntos, um referente à extensividade e outro à intensividade das ações, lançam o desafio de levar as iniciativas de saúde aos contextos mais distantes e de difícil acesso, às populações mais vulneráveis e tradicionalmente refratárias às ações de saúde.

O presente artigo se propõe a pensar a itinerância como "um modo" de operacionalizar o cuidado no território e algumas implicações éticas, teóricas e práticas daí decorrentes, problematizando o sentido que a itinerância adquire com a implantação do SUS, no contexto mais específico das transformações propostas pela Reforma Psiquiátrica e pela Reforma Sanitária, presentes nas atuais políticas de Saúde Mental e Atenção Básica.

A itinerância como modo de operacionalizar o cuidado no território traz consigo alguns questionamentos éticos. $\mathrm{O}$ primeiro questionamento necessário é pensar em que medida as práticas itinerantes, ao deslocarem as intervenções para o território de vida das pessoas - local onde os usuários estão inseridos em sua rede de relações e em sua situação material de existência -, expressam de fato uma mudança significativa na produção do cuidado em saúde. Entendemos que o mero deslocamento em um plano extensivo não garante a ruptura com as lógicas hegemônicas, normativas e reducionistas que as atuais políticas públicas de Saúde Mental e Atenção Básica visam combater: o deslocamento espacial pode ser uma simples estratégia de refinamento e capilarização do controle das populações.

Um segundo questionamento é saber em que medida esses deslocamentos no território produzem mudança no plano intensivo das práticas e dos territórios subjetivos dos usuários. Trata-se, nesse caso, de pensar o modo de operar itinerante como um constante deslocamento para além de um âmbito estritamente espacial, afirmando seu potencial de produzir um cuidado contextualizado ao território existencial dos usuários e de criar linhas de fuga ao mandato social de controle.

Entendemos que a experiência desses trabalhadores itinerantes, em função da complexidade e dos acidentes a que estão expostos em seus percursos, tem o potencial de produzir o estabelecimento de uma relação peculiar com o território 
e o rompimento com o instituído, abrindo assim espaço para a criação de novas produçôes de sentido no campo das práticas de cuidado em saúde. Pois, se é um fato que as práticas itinerantes operam um deslocamento espacial no ato de ir ao encontro do usuário em seu território de vida, resta saber qual o campo de possibilidade dessas experiências produzirem o movimento de acompanhar o usuário na construção e/ou ampliação de seu território existencial.

\section{A itinerância e a construção de uma lógica territorial de cuidado}

A itinerância tem tido um papel importante de articulação entre as atuais políticas de Saúde Mental e Atenção Básica:, em que o deslocamento das intervenções para o território de vida dos usuários passa a ter uma importância renovada. Nos documentos normativos referentes a essas políticas, predominam dois sentidos para a palavra território: o de "território adscrito" ou "âmbito de atuação", que é o uso da noção de território como recorte do espaço para organizar a atenção, regular o acesso e os fluxos e disciplinar as responsabilidades de usuários, trabalhadores e gestores, de acordo com o princípio organizativo de descentralização político-administrativa do SUS. O outro sentido, para o qual gostaríamos de chamar atenção, é o de território como um princípio constitutivo dos processos de trabalho e das práticas de cuidado, em direção à construção de um modelo de cuidado territorial (BRASIL, 2004a, 2004b, 2004c, 2005, 2007).

No contexto das referidas políticas, o princípio de desinstitucionalização, proveniente da Reforma Psiquiátrica, e o princípio de integralidade, proveniente da Reforma Sanitária, são operadores conceituais que marcam a diferença das transformações que as reformas se propõem a imprimir no cotidiano das práticas de cuidado. Ambos os conceitos - desinstitucionalização e integralidade - supõem um engajamento ético-político do trabalhador e o investimento do território como um plano de articulação de suas práticas de cuidado.

Podemos considerar a desinstitucionalização das práticas de cuidado, contribuiçãao advinda do campo da Reforma Psiquiátrica, como uma premissa ética do SUS, pois o princípio basilar da bioética da "não maleficência" afirma que, uma primeira atitude ética na constituição das práticas de saúde é pôr em questão e desconstruir todo saber, sistema explicativo, protocolo clínico e modelo de intervenção que produza efeitos iatrogênicos. Isso significa, portanto, 
problematizar os modos de olhar e de construir o objeto das práticas, os recortes epistemológicos produzidos e seus efeitos sobre os sujeitos das intervenções. A desinstitucionalização propõe desconstruir o recorte artificial que separa uma entidade abstrata de seu contexto existencial, a doença de seu território de emergência (ROTELLI, LEONARDIS, MAURI, 1992).

A integralidade é uma marca singular do SUS e sintetiza o ideário da Reforma Sanitária, diferenciando-a das práticas de viés reducionistas que se coadunam ao projeto neoliberal de interesse econômico na exploração do sofrimento e pobreza humanos. Segundo esse princípio, o cuidado deve ser contextualizado ao modo de vida dos usuários (MERHY, 2005), deslocando a tônica da demanda para as reais necessidades de saúde (MATTOS, 2001). Por outro lado, o princípio de integralidade estabelece como objeto de intervenção um sujeito em sofrimento no seu contexto de vida (PINHEIRO et al.; SILVA et al., 2005).

A itinerância sempre desempenhou um papel importante nas políticas de saúde do Brasil, como nas operações do sanitarismo campanhista de combate às endemias urbanas e rurais. Na Primeira República é possível citar experiências como a dos auxiliares de saneamento (RISI JUNIOR, NOGUEIRA, 2002), das visitadoras de higiene, das enfermeiras visitadoras (PEREIRA NETO, 1997) e das visitadoras psiquiátricas (CUNHA apud PALOMBINI, 2007) que foram orientadas por concepções higienistas e eugenistas, produzindo práticas normalizadoras que foram motores de um grande processo de controle sobre os modos de vida das populações pobres, sem preocupação alguma com suas condições materiais de existência (LIMA, 2002).

Com a institucionalização do SUS, a itinerância passa a ter relevância estratégica para a construção de um modelo de cuidado territorial que as políticas de Saúde Mental e Atenção Básica do sistema nacional de saúde passaram a exigir. É no delicado campo de articulação dessas políticas que três tecnologias de trabalho têm se destacado na tarefa de conferir ao território um lugar de plano articulador das práticas: as experiências dos acompanhantes terapêuticos (ats), dos Agentes Comunitários de Saúde (ACS) e dos redutores de danos, que são tecnologias que não obstante suas diferenças - guardam em comum a característica de operar em movimento e efetuar ações de cuidado no território de existência dos usuários. Essas três experiências adquiriram consistência própria e vinculam-se de modo estreito às problemáticas suscitadas pelos movimentos das reformas Sanitária e 
Psiquiátrica, e têm desempenhado um papel fundamental na construção de uma lógica territorial de cuidado no âmbito do SUS.

A Declaração de Alma-Ata, em 1978, já recomendava a figura de um agente comunitário, assim como a VIII Conferência Nacional de Saúde recomendou a adoção dos "agentes populares" para trabalhar com os cuidados primários em saúde (BRASIL, 1986). Mas foi justamente no ano seguinte à promulgação da Lei Orgânica da Saúde de 1990 que se institucionalizou a figura dos agentes comunitários de saúde com a criação, pelo Ministério da Saúde, do "Programa Nacional de Agentes Comunitários de Saúde" (PNACS).

Foi em Santos, berço de importantes experiências do Movimento Sanitário, em 1990, que surgiu a primeira experiência brasileira de trabalho de campo dos redutores de danos (SOUZA, 2007). Do mesmo modo, a Portaria MS 224 de 1992, primeira regulamentação relativa às políticas de Saúde Mental pós Lei Orgânica da Saúde, estabelece a visita domiciliar como uma ação das equipes de Saúde Mental na comunidade (BRASIL, 2004a).

Um tipo de atividade surgida no Brasil por volta dos anos 1960 em clínicas privadas, e que então já era denominada de Acompanhamento Terapêutico, vai aos poucos se inserindo nas políticas públicas e se afirmando como um "dispositivo clínico" da Reforma Psiquiátrica (PALOMBINI, 2006).

A III Conferência de Saúde Mental propôs a criação de "equipes volantes de saúde mental" que fossem orientadas pelos princípios da Reforma Psiquiátrica e funcionassem como referência para as equipes do Programa de Saúde da Família (PSF). A conferência também recomendou a implantação de serviços de atendimento ou de internação domiciliar em saúde mental que fossem realizados por "equipes itinerantes", por ACS ou ainda equipes do PSF (BRASIL, 2002, p. 50).

A possibilidade de pensar a itinerância como um modo singular de operacionalizar o cuidado no território parte de diversas experiências de atenção que têm sido construídas no cotidiano das práticas de saúde ao longo das duas últimas décadas e das reflexôes teóricas que surgem delas. Uma experiência que se tornou referência no país para a inserção de ações de Saúde Mental na Estratégia de Saúde da Família foram as Equipes Volantes de Saúde Mental do projeto Qualis. Em seu relato sobre essas experiências e ao estabelecer a partir daí uma "síntese metodológica", Lancetti (2002), coordenador do projeto, lançou as bases sobre as quais construiu a ideia de uma "clínica peripatética". 
As Equipes Volantes de Saúde Mental atuavam na comunidade tendo como princípio fundamental da metodologia de trabalho a produção de uma corresponsabilidade com as Equipes de Saúde da Família. Desse modo, deslocavamse pelo território adscrito dentro da "lógica de busca ativa", indo até as famílias em situação de maior vulnerabilidade em companhia dos ACS ou de algum técnico da ESF. Utilizavam o que o autor (LANCETTI, 2002) denominou de "fator surpresa" como estratégia de intervenção, dado que as visitas nos locais de vida das pessoas eram realizadas sem aviso prévio. Era um modo de evitar as habituais respostas dos usuários às habituais intervenções e desestabilizar os lugares instituídos. Segundo Lancetti (2006b), as açôes de saúde sustentadas pela surpresa se fundamentam na paradoxal relação de forças entre o poder de polícia médica dos profissionais de saúde e o poder de afetação que podem produzir nos encontros com o usuário. Quando esse jogo de forças é usado em defesa da vida, os trabalhadores de saúde atingem o que o autor chama de ascendência afetiva.

Além do princípio da corresponsabilidade entre as equipes, a prioridade aos casos mais graves e do fator surpresa, as equipes volantes tinham como princípio de trabalho que todas as ações fossem pautadas pelo conceito de cidadania, porque antes de qualquer indicador de patologia, o usuário é um cidadão. $\mathrm{O}$ segundo princípio é considerar que os usuários não padecem do corpo ou da mente separadamente, porque as condições ambientais, sociais e mentais são ecologias inter-relacionadas. O terceiro princípio afirma que os processos de produção de saúde devem ocorrer em diálogo com o universo existencial das pessoas. As equipes devem conhecer os sistemas que estruturam a vida do coletivo, os interlocutores invisíveis com os quais dialogam e os modos daquela cultura explicar e lidar com o sofrimento (LANCETTI, 2002).

Outro princípio proposto por Lancetti (2006b) é o da "complexidade invertida”. As ações de saúde realizadas na Atenção Básica são tradicionalmente consideradas ações de baixa complexidade, enquanto as ações realizadas em serviços, como centros cirúrgicos e grandes hospitais (Atenção Terciária), são consideradas de alta complexidade. Lancetti (2006b) defende a ideia de que, em se tratando de sofrimento psíquico, é exatamente o contrário: os procedimentos realizados dentro dos hospitais psiquiátricos são procedimentos simples e tendem à simplificação. A vida do paciente, na medida em que vai cronificando, tende a ficar cada vez mais empobrecida. Já as ações no território são muito 
mais complexas, com todos os atravessamentos sociais e culturais, as condiçōes materiais de vida e os riscos que comporta um setting que não é fixo e que impõe constantes deslocamentos aos trabalhadores.

Existem na literatura diversas denominaçōes para esse modo de operacionalizar o cuidado. Pelliccioli et al. (1987) utilizaram a expressão "clínica itinerante" para se referirem ao trabalho clínico realizado pelos acompanhantes terapêuticos (ats). Rolnik (1997) usou o termo "clínica nômade" para expressar um modo de cuidado que se dá no "fora" dos códigos instituídos, que ultrapassa os territórios conhecidos e sedentarizados, deixando-se afetar pelos fluxos e intensidades para além do mundo das representações. Palombini (2004) usou o termo "clínica em movimento" ao se referir às práticas dos ats, e Silva (2005) usou o termo "fazer andarilho". Lancetti (2006b) e Araújo (2006) usaram o termo "clínica peripatética" para definir esse modo de cuidado que pressupõe um deslocamento pelo território do usuário. Araújo (2006) usa o termo ao falar do acompanhamento terapêutico, sinalizando assim um modo de operar o cuidado que se dá sem local fixo, nos passeios, nos percursos de saídas. Lancetti (2006b) usa o termo "práxis peripatética" para designar as diversas experiências de produção de saúde que se dão peripateticamente, ou seja, em movimento.

Petuco e Medeiros (2008) usam o termo "clínica aberta" para designar o trabalho dos acompanhantes terapêuticos e dos redutores de danos. Os autores consideram a clínica aberta, antes de uma questão de método, uma experiência ética dos trabalhadores de saúde que só se atualiza na práxis, pois as ações de uma clínica aberta são assentadas no acolhimento radical dos usuários em sua diferença. Segundo os autores, essa práxis dos acompanhantes terapêuticos e dos redutores de danos tem como efeito produzir um tensionamento constante a todo tipo de institucionalização das práticas de cuidado.

Souza (2007), ao falar do trabalho dos redutores de danos, considerou este uma modalidade de "clínica a céu aberto" que tem o desafio de se constituir como uma práxis que afirme o território como um espaço de produção de subjetividade. Lancetti (2006a) também usa o termo "clínica cartográfica" para se referir às práticas de saúde que possuem um setting móvel, em contraposição às práticas que utilizam um setting fixo, e que, segundo o autor, produzem uma "clínica arqueológica". 
Em Porto Alegre, a equipe de saúde mental da Pensão Protegida Nova Vida

adotou um modo de trabalho itinerante. Segundo a equipe, a itinerância foi uma resposta à exigência de criação de novas formas de intervenção no trabalho com portadores de sofrimento psíquico, para os quais os modos tradicionais de atenção não davam conta das necessidades de saúde que surgiam no decorrer dos processos de inserção social. Para a equipe, ficou claro que os integrantes teriam de deslocar suas intervenções para fora do espaço protegido dos estabelecimentos. Adotou, assim, a itinerância como novo modo de atenção, realizando as intervenções fora das habituais instituições, as quais nomearam Atendimentos Domiciliares Terapêuticos, para inscrever suas ações no marco das intervenções em saúde, ao invés da tradicional Visita Domiciliar (GUILHERME NETO et al., 2004).

A itinerância passou a ser o recurso utilizado para operacionalizar as intervenções no "lugar onde estava o usuário" - na sua casa, na pensão, na família ou na rua -, realizando ações das mais diversas complexidades, como acompanhar o usuário nas compras, no seu convívio com os vizinhos, nos conflitos familiares e no cuidado com os filhos. Consideram que ao “"ingressarmos terapeuticamente” no mundo do nosso usuário, estamos construindo junto com ele novas formas de morar, de se relacionar e de viver" (GUILHERME NETO et al., 2004, p. 22, 23 [Grifos dos autores]). Também relatam que, com suas experiências, puderam verificar que, mesmo no trabalho com usuários com transtornos psíquicos severos e/ou longo histórico de institucionalização, "é possível construir um novo caminho, refazer histórias, histórias inéditas, incluídas num social que forçosamente vai se desestabilizar” (GUILHERME NETO et al., 2004, p. 23).

Os autores dessa experiência consideram sua prática um trabalho processual e permanentemente aberto à modificação: “... é um modo de trabalho onde é permitido experimentar o caminho, errar, desconstruir e construir novamente” (GUILHERME NETO et al., 2004, p. 23). Por último, os autores conceituam a itinerância tanto como o movimento realizado no ato de ir ao encontro do usuário, como os movimentos que se produzem ao acompanhar o usuário na comunidade, garantindo o seu pertencimento a um território. A equipe também considera itinerância a abertura de novos caminhos que o pensamento percorre em decorrência da complexidade das práticas. 


\section{O problema da percepção do movimento}

Para pensar a itinerância como um modo de operacionalizar o cuidado no território, é necessário considerar o problema da percepção do movimento. Bergson (2006) considera um erro confundir o movimento com aquilo que se percebe estritamente no extenso percorrido. Um trabalhador da saúde sai da UBS, o ponto A, e vai até a casa de um usuário, ponto $\mathrm{B}$. Do ponto $\mathrm{A}$ ao $\mathrm{B}$ podemos dizer que o trabalhador percorreu dez quadras, contando cada esquina que ele atravessou. Segundo o autor, com esse cálculo não estamos apreendendo a natureza do movimento, estamos apenas medindo o espaço percorrido por um móvel, as suas paradas ou as passagens por pontos estáticos. Ou seja, nós estamos confundindo o movimento com um plano estático. "Como poderia o movimento aplicar-se sobre o espaço que percorre?”, pergunta o autor (BERGSON, 2006, p. 164).

É que, para Bergson (2006, p. 165), “o movimento é a própria realidade” e o que percebemos como estático é um efeito semelhante ao que ocorre quando, em duas linhas paralelas de trem, um passageiro de uma linha tem a impressão de ver um passageiro da outra linha parado atrás de sua janela, enquanto ambos estão em movimento. Desse modo, perceber um objeto como imóvel é uma questão de ajuste de velocidades e direçôes dos móveis. $\mathrm{O}$ autor considera que pelas necessidades práticas dos automatismos do cotidiano é apenas a percepção da imobilidade que guardamos e dela fazemos um absoluto.

Segundo o autor, num deslocamento, não é o movimento que nossa percepção e atenção costumam apreender, "são as próprias posições, aquela que o móvel deixou, aquela que ele assumirá, aquela que ele assumiria caso parasse no meio do caminho" (BERGSON, 2006, p. 165), porque precisamos da imobilidade para tentar compreender o movimento. Nossa percepção, presa à condição de mero auxiliar do replicar mecânico das ações cotidianas, é constantemente recortada pelas necessidades da vida prática. Antecipadamente classifica e etiqueta os objetos percebidos: "mal olhamos o objeto, basta-nos saber a que categoria pertence" (BERGSON, 2006, p. 158). É pelas margens do rio que pensamos compreender seu fluxo. Nesse sentido, para o autor, o papel do pensamento é ampliar a percepção do real por meio de um "deslocamento da atenção" e "romper com certos hábitos de pensar e de perceber que se nos tornaram naturais" (BERGSON, 2006, p. 163).

Segundo o autor, "diante do espetáculo dessa mobilidade universal, alguns dentre nós serão tomados de vertigem. Estão habituados à terra firme; não 
conseguem se acostumar ao jogo e ao balanço do mar. Precisam de pontos "fixos" aos quais fixar a vida e a existência" (BERGSON, 2006, p. 173) e afirma que é necessário se tranquilizar, pois se olharmos o movimento e a mudança sem nenhum "véu interposto", iremos perceber que o movimento é constitutivo da realidade e o que pode haver de mais sólido, substancial e durável.

Bergson (2006) afirma que todo movimento é indivisível, não pode ser reduzido ou decomposto segundo a trajetória que desenhou. $\mathrm{O}$ fato de podermos tomar o espaço e dividi-lo metricamente, como a um tabuleiro de xadrez, não significa que possamos fazer isso com o movimento. Mesmo que uma caminhada, por exemplo, seja uma série de atos indivisíveis, (um passo depois do outro), não é possível decompor a caminhada segundo os critérios de uma outra lei, como a do espaço percorrido, em que podemos reter as posições assumidas, mas não as transposições. Do mesmo modo, o movimento não implica a existência de um móvel, não precisa do suporte de coisas que se movam, mesmo porque, segundo o autor, não existe um objeto inerte ao qual o movimento possa vir a se somar. Bergson (2006, p. 171) indaga: "O que é o móvel ao qual o nosso olho vincula o movimento como que a um veículo? Simplesmente uma mancha colorida, que sabemos bem que se reduz, em si mesma, a uma série de oscilações extremamente rápidas". Porque o real é a própria mobilidade, num devir universal.

Se agora passamos a considerar a aparente imobilidade de um atendimento sentado em uma cadeira ou sobre um leito, um arranjo efêmero entre diversas mobilidades, mera questão de ajuste entre velocidades e trajetórias, é preciso pensar: numa prática itinerante, qual a amplitude do leque em termos de qualidades de movimentos que está em causa? Podemos concluir que o movimento no plano espacial perde sua importância diante do "fluxo torrencial" da realidade. Supomos, a partir daqui, que o movimento no plano espacial guarda uma importância apenas relativa, e em dois aspectos: como valor descritivo e como fator de exposição. Valor descritivo porque transforma o corpo num móvel facilmente identificado por nossa percepção habitual. Fator de exposição porque, ao se deslocar, os trabalhadores se expõem tanto à complexidade movente de um território como aos acidentes e imprevistos dos itinerários. Perceber o devir universal é perceber que não se está em movimento sobre um território estático, mas que os percursos se desenham num território vivo e complexo, um campo movente de intensidades. 
Um modo possível de pensar a complexidade movente do território é através do rizoma, um modelo para pensar a multiplicidade, proposto por Deleuze e Guattari (1995). Através do rizoma, podemos pensar o território não mais como um extenso estático, mas como um plano de consistência - zona de intensidade contínua - composto por uma multiplicidade de dimensões crescentes, que se conecta por linhas a outros planos. Essas linhas conectam um ponto a qualquer outro, ligando traços de natureza heterogênea, produzindo conexôes de regimes semióticos diferentes, conectando fluxos biológicos, políticos e econômicos com as maquinarias sociais, as organizaçôes de poder e os movimentos sociais. Diferente de um mapa estático, a multiplicidade e a conectividade de um rizoma possibilitam a produção de agenciamentos criativos e a composição de uma cartografia móvel, cujos contornos vão se transformando, conforme o desenho dos percursos.

Cartografia é um termo pelo qual se designa toda uma abordagem de produção de conhecimento que tem sido utilizada como estratégia de estudo no âmbito da subjetividade. Alguns autores destacam seu potencial de intervenção no campo nas práticas sociais (KASTRUP, 2007b, 2008). Rolnik (2006) afirma que os relevos formados pelas paisagens psicossociais também podem ser cartografados. Segundo Deleuze e Guattari (1995) uma cartografia pode ser traçada como ação política ${ }^{1}$.

Para apreender o desenho de uma cartografia móvel, é necessário, segundo Kastrup (2007b) cultivar um tipo especial de atenção, que consideramos ser de inestimável valor para as intervençôes nas práticas de cuidado no território. Segundo Kastrup (2007b), a cartografia é sempre de um território existencial, porque não é possível dissociar a subjetividade de suas conexões com o mundo, sua rede processual de produção: um agenciamento de vetores, forças e linhas que atuam simultaneamente, sempre em movimento. Desse modo, configuram um rizoma, que é o campo intensivo no qual a subjetividade se produz numa relação criativa. Segundo Rolnik (2006), uma cartografia no território se ocupa das estratégias de produção de desejo no campo social - como são os movimentos sociais, as transformações nos modos de sensibilidade e manifestações, como a violência e os quadros clínicos.

Ao se deslocar com sua práxis no território, um cartógrafo deve levar consigo um critério estético, um princípio ético-político e certa modulação da percepção. $O$ critério estético é usar qualquer matéria de expressão que possa formar composições que deem consistência ou ampliem os territórios existenciais. O princípio ético é 
eleger composições que sustentem o movimento de expansão da vida. O princípio político é incidir na micro-política dos modos de subjetivar, de modo a ampliar o desejo como produtor de constelações existenciais (ROLNIK, 2006).

Segundo Kastrup (2008), a cartografia tem um caráter político de intervenção, porque ao fazer o traçado de um campo de forças, o cartógrafo é conduzido pelo desejo de produzir inflexões no estado de coisas. Quando são detectadas e evidenciadas certas linhas do rizoma que se encontram presas, bloqueando o movimento, ou linhas que se encontram soltas, pedindo um novo agenciamento para tornar mais consistentes os territórios existenciais, ao trabalhar sobre essas linhas, o cartógrafo incide nos processos de produção de subjetividade, liberando os fluxos, produzindo novas conexões e, dessa forma, atualizando virtualidades.

Quanto à modulação da percepção, o que define um cartógrafo é o exercício de sua sensibilidade estética. É preciso estar receptivo às intensidades que se produzem e circulam em um território (ROLNIK, 2006). Deleuze (2009) fala que a postura de um animal territorial é um constante "estar à espreita". Um animal territorial está sempre à espreita da emergência de algum signo que evidencie um acontecimento e exija o disparo de alguma operação. Do mesmo modo, segundo Kastrup (2008), o cartógrafo, ao se imiscuir em determinado território existencial, parte antes de tudo em busca de signos, portanto deve manter essa atitude à espreita. Os territórios existenciais são compostos por regimes de signos, cada um com sua lógica e sua semiótica. Os cruzamentos dos regimes de signos ajudam a entender a configuração de um território. A autora usa como exemplo alguns regimes que, de algum modo, estão sempre presentes nas práticas de saúde: signos religiosos, familiares, de violência e sexuais.

A composição de uma cartografia é o desenho de um campo problemático composto pelos signos. Os signos demarcam os limites de um território, e é por meio deles que seus limites podem ser ampliados. São pontos de intensidade que afetam e forçam o cartógrafo a pensar. Eles são índice de uma urgência que emerge no território, seja a existência de um nó a ser desatado, seja uma linha solta que pode realizar conexóes produtivas para reativar os processos de invenção (KASTRUP, 2008). A atenção a esses pontos de intensidade é o que Eirado e Passos (2004) definem como estar receptivo às exigências de criação, às virtualidades que assombram e transbordam, ao que existe de excesso nas formas atuais e pede passagem para um novo devir. 
Kastrup (2007a, 2007b) alega que, para estar receptivo aos signos que emergem no território, o cartógrafo precisa cultivar um tipo especial de atenção, que é, ao mesmo tempo, flutuante, concentrada e aberta ao presente, capaz de entrar em sintonia fina com as intensidades do território existencial. Uma atitude atencional de ativa receptividade às forças circulantes e pontas de processo em curso que emergem no campo. Uma atenção que não caia num relaxamento passivo e tampouco uma atenção concentrada que selecione percepções e opere apenas com as formas já conhecidas.

As ações no território pautadas pela desinstitucionalização exigem a suspensão do "já conhecido" para queo pensamento opere com algo diferente das cristalizações de localizaçôes identitárias (esquizofrênico, bipolar, adicto) e se apoie num tipo especial de atenção ao território existencial dos usuários. Do mesmo modo, a integralidade exige uma amplitude de olhar sobre o território e uma atenção voltada à sua processualidade, para que se perceba a tônica da necessidade em uma intensidade que emerge no cipoal de complexidade do território. Seja uma relação que se tornou opressora, um modo de ser despotencializado diante da vida, uma afecção no corpo ou um direito social obstruído.

A importância dos princípios da cartografia para a operacionalização das práticas de cuidado no território não reside apenas no seu potencial de ativar a percepção na apreensão das linhas e dos nós problemáticos que compõem um território existencial. Sua importância está, sobretudo, no seu caráter de intervenção, no seu potencial de criar ou ampliar territórios existenciais ao liberar canais estancados e dar passagem a intensidades bloqueadas. A cartografia é um exercício político de colocar em perspectiva os limites de um território, evidenciado pelos seus nós, apontando os caminhos possíveis para a ampliação de suas fronteiras em defesa dos movimentos de expansão da vida.

\section{A itinerância como modo de operacionalizar o cuidado no território}

Para pensar a itinerância como um ethos do cuidado, um modo de estar e de se mover no território produzindo saúde, gostaríamos de retomar o conceito da equipe itinerante da Pensão Nova Vida. Seguindo o texto que a equipe construiu com base em suas experiências, podemos decompor seu conceito de itinerância nas práticas de cuidado em três elementos: 1) O movimento realizado no ato de 
ir ao encontro do usuário; 2) Os movimentos que os trabalhadores produzem ao acompanhar o usuário no processo de construir seu pertencimento a um território; 3) O movimento de desestabilização que a invenção de novos caminhos produz no pensamento e no real social (GUILHERME NETO et al., 2004).

O primeiro elemento do conceito agrupa um número enorme de experiências e não pode diferenciar as práticas itinerantes que operam sob a égide dos princípios do SUS, principalmente a desinstitucionalização e a integralidade, de práticas meramente higienistas, como as do sanitarismo campanhista da Primeira República. O segundo e o terceiro elementos já demarcam uma diferença. Não se trata mais de um simples pragmatismo de acesso com o objetivo de alcançar fisicamente os usuários - pragmatismo que pode estar tanto a serviço do controle de populações como da promoção de saúde. Trata-se do movimento político de agir em contato com os elementos do território do usuário, afetando de algum modo esse território e sendo afetado por sua complexidade.

O primeiro elemento do conceito aponta para um movimento num plano extenso. É um fato que a itinerância como modo de operacionalizar as práticas implica o movimento sobre um plano espacial. E, produzir um deslocamento que se dê estritamente no plano espacial, pode resultar apenas na ampliação da extensão de cobertura de um modelo de atenção, como o modelo sintomatológico, não implicando necessariamente alguma mudança nas práticas.

Tenório (2001) denomina de "modelo sintomatológico" o que orienta práticas reducionistas que não levam em conta a complexidade do território existencial dos usuários. Esse modelo tem como principal característica supor que o sintoma é um mal em si a ser "debelado". O modelo subordina o conjunto de saberes a um paradigma estritamente técnico-científico, centrando toda a sua atenção na pura expressividade dos sintomas e estabelecendo como único objetivo a sua mitigação. É um modelo de atenção em que a finalidade se reduz a obter resultados fixos, determinados previamente. Desse modo, impede a produção de um cuidado territorial por operar apenas com lógicas exógenas ao território dos usuários. Nesse modelo, o contato com o usuário tem a única finalidade de identificar sintomas que, catalogados, irão determinar uma conduta terapêutica. As práticas terapêuticas se reduzem então a um monitoramento de sintomas, em que não há preocupação alguma com as possíveis articulações destes com a dramática da existência ali colocada, a história do sujeito, seu território de vida e sua rede de relações. 
Já o segundo e o terceiro elementos apresentados apontam para a produção de movimentos de outra qualidade, movimentos que produzem algum tipo de diferença, seja na vida do usuário, seja no real social, no pensamento do trabalhador ou no plano das práticas.

Como afirmamos anteriormente, o movimento no plano espacial guarda uma importância relativa como fator de exposição. Fator de exposição porque, ao se deslocar, os trabalhadores se expõem tanto à complexidade movente de um território como aos afetos, acidentes e encontros dos itinerários que produzem desestabilizações. A exposição à complexidade do território contribui para a construção da integralidade do cuidado, assim como a desestabilização produzida pelos imprevistos contribui para a desinstitucionalização das práticas. O primeiro nível de exposição territorializa o pensamento aos modos de vida dos usuários, contextualizando as práticas de cuidado. O segundo nível de exposição desterritorializa o pensamento possibilitando a invenção de saídas criativas, a criação de linhas de fuga.

Esse é um campo de possíveis que a itinerância constitui para a ética do cuidado no território - traçar, a partir do fator de exposição, um plano intensivo que permita explorar a potência política do movimento. Um plano que não restrinja o movimento à extensão da cobertura da atenção, mas também amplie a possibilidade de produzir mudança nas práticas e no real social ao deslocar a natureza do próprio movimento.

Não é possível pensar o trabalho clínico de acompanhar os usuários no processo de construir seu pertencimento a um território como uma vinculação unilateral de um sujeito a um território naturalizado, pois como indica o terceiro elemento do conceito de itinerância, nesse processo o próprio território vai se desestabilizar (GUILHERME NETO et al., 2004). Segundo os autores da desinstitucionalização, para fazer caber a diferença no corpo social é necessário um trabalho inventivo de projetos de vida e de novos regimes de sociabilidade. Esse é um componente estético do trabalho itinerante: acompanhar os usuários na apropriação dos meios para constituir ou ampliar seus territórios de existência.

Segundo Deleuze e Guattari (1997a, 1997b) um território é produto de uma apropriação subjetiva de matérias de expressão, de elementos do espaço que deixam de ser apenas funcionais e se tornam expressivos. Essas matérias de expressão são signos, que desenham os contornos do território que pertencerá 
ao sujeito - que as carrega no corpo, produz ou utiliza. Esses limites não são espaciais, mas semióticos. Para tomar consistência territorial, as matérias de expressão precisam de certo "alcance espacial" e certa "constância temporal", assim como uma "distância crítica". Pois é a distância que permite a um sujeito se diferenciar, criar um estilo singular de existência, um modo de habitar, um ethos.

$\mathrm{O}$ conceito de agenciamento ajuda a pensar o movimento de acompanhar os usuários na construção ou ampliação de seus territórios existenciais. $\mathrm{O}$ agenciamento é o modo pelo qual o desejo como força em estado bruto se territorializa, porque o desejo requer ser agenciado para produzir território (GUATTARI; ROLNIK, 1987).

Segundo Deleuze e Guattari (1997b), um agenciamento é uma conexão de componentes heterogêneos que adquirem consistência e produzem o acoplamento de relaçóes materiais com um regime de signos. Um agenciamento produz território quando alguns signos adquirem valor de propriedade e passam a demarcar esteticamente os limites de uma apropriação subjetiva. Possui duas dimensões, por um lado é agenciamento de enunciação e por outro é agenciamento maquínico. A primeira dimensão é a sua expressão que comporta um sistema semiótico, um regime de signos. A segunda dimensão é o seu conteúdo, que comporta um sistema pragmático de ações. Num agenciamento sempre há relação de pressuposição recíproca entre estas duas dimensões.

No processo de territorialização do desejo, diferentes tipos de agenciamentos se articulam e se alternam e possuem componentes que servem como vetor de passagem de um a outro. Os "componentes de passagem" formam pontes, acesso e são os responsáveis pela formação de novos agenciamentos no seio de um agenciamento territorial. É a partir do agenciamento territorial que se parte para outros agenciamentos, sociais e sexuais (DELEUZE; GUATTARI, 1997b).

Essa noção de componentes de passagem tem enorme importância clínica, pois é de agenciamento em agenciamento que se constroem ou se ampliam territórios existenciais e que a vida pode seguir seu curso de expansão. A partir dessa noção os trabalhadores de um residencial terapêutico, por exemplo, podem vislumbrar melhor o potencial clínico dos diversos elementos expressivos do cotidiano. O cheiro do café que um usuário aprende a passar depois de anos de institucionalização num manicômio produz território, é um elemento de agenciamento territorial (ir ao bar de minha escolha, andar pela minha rua, 
escolher as marcas de café e filtro, meu próprio fogão, bule, cozinha, modo de preparo e o cheiro que se espalha pela minha moradia como uma melodia). O cheiro de café ultrapassa os limites da moradia e ganha a rua. A partir daí pode facilmente se converter em um componente de passagem do agenciamento territorial a outro agenciamento, social ou sexual. Um vizinho sente o cheiro e vem visitar, um começo de conversa, começo de amizade ou início de namoro. $\mathrm{O}$ cheiro de café passa a ser um conversor de agenciamento.

Pensando dessa forma os elementos do cotidiano passam a ter outro sentido. Constituir uma moradia, comprar a toalha que enfeita a mesa, os quadros da parede, as roupas do corpo e as contas de luz deixam de ser banalidades do dia a dia, meras questôes "extraclínicas", e adquirem grande importância na constituição de um território existencial e na produção de saúde. A consistência de um agenciamento pode emergir dos elementos mais simples, dos quais extrai toda força contida nos materiais.

Para o trabalhador itinerante se lançar à tarefa de ampliar territórios existenciais ele precisa explorar a potência política de sua condição de outsider. Não basta trabalhar ao ar livre, "fora” apenas dos módulos assistenciais É necessário manter um grau de desprendimento, uma posição de exterioridade em relação às coordenadas de referência dominantes, como a de certas racionalidades estritamente técnicas e aos modos de olhar que aprisionam em formas identitárias. Ao se deslocar mantendo uma posição de exterioridade no plano intensivo das práticas, os trabalhadores itinerantes realizam o que Deleuze e Guattari (1997b) denominam agenciamento nômade, que é a produção de um movimento em velocidades intensivas que desestabiliza as cristalizações do instituído e abre um espaço de topologia lisa, livre de constrangimentos burocráticos. Esse espaço liso, como a estepe dos nômades, é propício para a produção de um movimento mais potente e para a invenção de saídas criativas. Ao falar de topologia lisa no plano intensivo das práticas, estamos nos referindo ao modo de se mover e habitar o território, de produzir e construir intervenções, de travar relações com a alteridade do usuário, de modular a percepção e operar o pensamento.

Nas práticas, produzimos espaço liso cada vez que rompemos com um tipo de relação burocrática com o território e deixamos de confundi-lo com demarcações que provêm de lógicas exógenas a ele e, em vez do repertório de movimentos rigidamente delimitados, nos movemos livres de uma razão 
burocrática, compondo uma cartografia móvel. Uma equipe de saúde produz um agenciamento nômade, quando, por exemplo, através de suas movimentações, consegue desterritorializar o modo como uma família ou uma comunidade vê um louco ou um morador de rua. Com suas intervençôes, com seu modo de pensar e olhar a diferença, esses trabalhadores que não aceitam aprisionar pessoas em formas identitárias (constrangimentos sedentários ao movimento) acabam corroendo os lugares instituídos e produzem agenciamentos criativos cujos efeitos clínicos potencializam a vida. Um redutor de danos compóe um espaço liso ao prescindir das codificações morais em relação ao uso de drogas e suas divisões dicotômicas e propõe - sobre a consigna da cidadania - uma multiplicação de caminhos possíveis, diferentes dos caminhos socialmente cristalizados, que produzem uma resposta tão dura.

Construir um espaço liso nas práticas de cuidado no território é compor um campo de consistência onde o pensamento pode adquirir velocidade absoluta, uma aceleração propícia aos movimentos de criação. No trabalho no território, esse espaço liso pode ser pensado como tendo função análoga à função que o setting tem para as diversas práticas psi. A produção desse espaço liso, desse espaço diferencial, dar-se-ia colocando as práticas de saúde e seu arsenal técnico sob novas bases, que incluam o plano da afectabilidade e uma profunda conexão com o território existencial dos usuários. Habitando esse espaço em suas práticas, o trabalhador pode acessar o plano das intensidades e se tornar um artesão de territórios existenciais e um produtor de linhas de fuga. É nesse espaço que o pensamento suspende a razão burocrática, adquire a sua potência própria de criação e pode produzir o que os autores da desinstitucionalização denominam "invenção de vida". Colocar efetivamente a "doença mental" entre parênteses, suspender um conjunto moral de codificações (ROTELLI, et al.; 1992; AMARANTE, 1996; BASÁGLIA, 2005), para ver emergir a vida e o desejo é uma estratégia de guerra nômade. Assim como prescindir das racionalidades que produzem medicalização e controle da vida.

Esse ato de violência contra a força do instituído, que é o agenciamento nômade, é um modo de pensar o terceiro elemento do conceito de itinerância da equipe da Pensão Nova Vida, que se refere aos efeitos de desestabilização que os itinerários produzem tanto no real social como no pensamento e no plano das práticas (GUILHERME NETO et al., 2004). 


\section{Considerações finais}

A itinerância como modo de operacionalizar as práticas de cuidado sempre teve importância nas políticas de saúde no Brasil. No período da Primeira República, foi fundamental nas operaçôes do sanitarismo campanhista, no combate às endemias rurais e epidemias urbanas. As práticas itinerantes orientaram-se pelas concepçōes científicas de cada período, e quando se orientaram por concepções higienistas e eugênicas, estiveram envolvidas em ações autoritárias no saneamento dos espaços urbanos, como desalojamentos, imposição de vacinação ou quarentena.

Com a emergência do SUS como um processo resultante das lutas da Reforma Sanitária e Reforma Psiquiátrica, a noção de território tomou a dimensão de princípio organizador dos processos de trabalho, notadamente nas políticas de Atenção Básica e Saúde Mental. Nesse contexto, e diante dos princípios éticos de universalidade, equidade, integralidade, desinstitucionalização e autonomia, as práticas itinerantes sofreram uma torção e passaram a ter uma importância estratégica nesse campo delicado de articulação entre as políticas de Saúde Mental e Atenção Básica, na construção da integralidade do cuidado e na desinstitucionalização das práticas no território. Podemos considerar a desinstitucionalização e a integralidade como os operadores conceituais que marcam a diferença que as reformas Psiquiátrica e Sanitária pretendem imprimir nas práticas de cuidado em relação ao modelo sintomatológico, que sintetiza tanto as racionalidades do manicômio como as da proposta reducionista da medicina neoliberal.

Pelo acoplamento das racionalidades do modelo sintomatológico, as práticas itinerantes correm o constante risco de carregar muitos de seus vícios higienistas e funcionarem como uma peça do aparelho do Estado no controle racional das populações e no silenciamento das diferenças incômodas, ao embrenhar-se numa postura de busca ativa, com fluidez no território de vida dos usuários. Não obstante, mesmo que com o deslocamento das práticas de saúde para o território se corra o risco de estar produzindo capilarização das técnicas de controle, é preciso lembrar que no território as relaçôes de poder tendem a ser mais móveis, reversíveis e instáveis, assim como as estratégias de resistência mais complexas, porque o usuário é um sujeito político e o território é uma arena de lutas, onde há conflitos, jogos de força e diferentes regimes de sociabilidade. 
Ao operar "fora" de uma lógica estritamente sintomatológica, é possível construir uma lógica territorial de cuidado que se traduz em produção de práticas de respeito ao mundo do usuário e em sintonia com seu modo de vida. Num modelo territorial de cuidado, os operadores conceituais de desinstitucionalização e integralidade são essenciais, pois ambos se articulam e agem no duplo sentido de proteger o usuário da violência da imposição de lógicas exógenas ao seu modo de vida e de amarrar as práticas a esses modos de vida, contextualizando as problemáticas na complexidade que lhes são inerentes.

Para não sucumbir a uma mera estratégia de controle, é necessário traçar um plano intensivo que explore a potência política do movimento. A partir desse plano, é possível transmutar as ações da replicação técnica de um mero pragmatismo de acesso em um engajado agir político criativo, no qual a responsabilização pelo cuidado passa a ser - usando palavras de Arendt (2005) - uma questão de amor aos negócios do mundo; o acolhimento, uma postura de atenção às necessidades postas na complexidade movente do território; e o vínculo, uma constante temporal que ajuda a dar consistência a territórios existenciais.

$\mathrm{O}$ que permite aos trabalhadores itinerantes deslocar a natureza de seus movimentos é o coeficiente de transversalidade e desprendimento que conseguem manter. $\mathrm{O}$ coeficiente de transversalidade refere-se à possibilidade de transitar entre os diversos paradigmas que operam nas práticas, entre o paradigma técnico-científico e o estético, entre as linhas molares e moleculares. $\mathrm{O}$ coeficiente de desprendimento refere-se à possibilidade de operar fora dos sistemas de referência dominantes, criando linhas de fuga. Uma maior transversalidade e um maior desprendimento afastam as práticas da reprodução e as aproximam do processo de criação.

O movimento empreendido pelas caminhadas dos trabalhadores itinerantes, além do valor pragmático de acesso, tem uma importância referente ao seu valor como fator de exposição. Primeiro porque territorializa o pensamento em sua conexão com as práticas de cuidado aos territórios existenciais dos usuários. Segundo porque pode produzir desterritorialização e possibilitar a criação de linhas de fuga, quando o pensamento e percepção adquirem aceleração por serem atingidos por um vetor desestabilizante, um acidente, um encontro, um afeto. 
Para finalizar, a partir dos conceitos desenvolvidos no corpo deste trabalho, entendemos que as diversas práticas de cuidado dos trabalhadores itinerantes têm apontado para a construção de uma ética territorial do cuidado no âmbito do SUS.

Com a cartografia, como estratégia de inserção no território, podemos entender que essa ética se refere a compreender o território não como um extenso estático, mas um campo de complexidade, que requer a modulação da atenção e do olhar para as problemáticas do território, que são evidenciadas por signos das mais diversas proveniências, rompendo com um olhar culpabilizante que responsabiliza o indivíduo por problemas sociais e evidenciando que existe uma multiplicidade de formas e entradas para se tecer linhas na produção do cuidado. As experiências de desinstitucionalização nos mostram que esse olhar deve se desvencilhar das pré-concepções e dos sistemas explicativos que turvam a percepção e servem ao aprisionamento identitário, à mistificação e ao estabelecimento de um circuito fechado que impede a produção de saídas criativas. As construçôes conceituais sobre a integralidade nos mostram que esse olhar deve ser capaz de restituir a complexidade dos objetos de nossas intervençôes encontrando as conexões da problemática com o contexto de vida dos usuários, pois essas conexões podem apontar uma infinidade de caminhos na construção do cuidado. Cultivar a percepção dessa forma permite romper com a ética normalizadora na saúde e explorar a potência política do movimento na construção/ampliação dos territórios existenciais dos usuários no âmbito das práticas de cuidado no território.

A itinerância produz uma ética de cuidado quando deixa de ser apenas um recurso pragmático de acesso e, ao usar a potência do movimento, consegue transformar o território num laboratório de experimentação política e de invenção de novos modos de existência.

\section{Referências}

AMARANTE, P.D.C. O homem e a serpente: outras histórias para a loucura e a psiquiatria. Rio de Janeiro: Fiocruz, 1996.

ARENDT, H. A condição humana. Rio de Janeiro: Forense Universitária, 2005.

ARAÚJO, F. Um passeio esquizo pelo acompanhamento terapêutico: dos especialismos à política de amizade. Niterói: Fábio Araújo, 2006.

BASAGLIA, F. O circuito do controle: do manicômio à descentralização psiquiátrica. In: AMARANTE, P.D.C. (Org). Escritos selecionados em saúde mental e reforma psiquiátrica Franco Basaglia. Rio de Janeiro: Garamond, 2005. p. 237-257. 
BERGSON, Hi. O pensamento e o movente: ensaios e conferências. São Paulo: Martins Fontes, 2006.

BRASIL. Ministério da Saúde. Conselho Nacional de Saúde. Relatório Final da VIII Conferência Nacional de Saúde Mental, Brasília: Biblioteca Virtual do Conselho Nacional de Saúde. 17 a 21 março de 1986. Disponível em: < http://conselho.saude.gov.br/biblioteca/ Relatorios/relatorio_8.pdf> Acesso em: 14 fev 2009.

BRASIL. Ministério da Saúde. Conselho Nacional de Saúde. Relatório Final da III Conferência Nacional de Saúde Mental, Brasília: Centro de Documentação da Saúde, 2002.

- Departamento de Açôes Programáticas Estratégicas. Saúde Mental no SUS: os Centros de Atenção Psicossocial. Brasília: Ministério da Saúde, $2004 \mathrm{~b}$.

- Secretaria de Atenção à Saúde. Coordenação Geral de Saúde Mental. Reforma psiquiátrica e política de saúde mental no Brasil. Documento apresentado à Conferência Regional de Reforma dos Serviços de Saúde Mental: 15 anos depois de Caracas. Brasília: OPAS, nov. 2005.

. Secretaria de Atenção à Saúde. Departamento de Atenção Básica. Política Nacional de Atenção Básica. Brasília: Ministério da Saúde, 2007.

Secretaria de Atenção à Saúde. Legislação em Saúde Mental. 1990 - 2004. Brasília: Ministério da Saúde, 2004a.

- Secretaria de Atenção à Saúde. SVS/CN-DST/AIDS. A Política do Ministério da Saúde para Atenção Integral a Usuários de Álcool e Outras Drogas. 2. ed. rev. ampl.- Brasília: Ministério da Saúde, 2004c.

DELEUZE, G. O Abecedário de Gilles Deleuze: entrevista realizada por Claire Parnet entre os anos 1988-1989. Disponível em: http://www.oestrangeiro.net/index.php?option=com content\&task=view\&id=67\&Itemid=51 Acesso em: 03 fev. 2009.

DEleuZE, G.; GUATTARI, F. Acerca do Ritornelo. In: Mil platôs, capitalismo e esquizofrenia, v. 4. Rio de Janeiro: Ed34, 1997a. p. 115-170.

Introdução: Rizoma. In: Mil platôs, capitalismo e esquizofrenia, v. 1. Rio de Janeiro: Ed34, 1995. p. 11-37.

. Tratado de Nomadologia: a máquina de guerra. In: Milplatôs, capitalismo e esquizofrenia, v. 5. Rio de Janeiro: Ed34, 1997b. p. 11-110.

EIRADO, A.; PASSOS, E. A noção de autonomia e a dimensão do virtual. Psicologia em Estudo. Maringá, v. 9, n. 1, p. 77-85, 2004.

GUATTARI, F.; ROLNIK, S. Micropolitica: cartografias do desejo. Petrópolis: Vozes, 1986. KASTRUP, V. O funcionamento da atenção no trabalho do cartógrafo. Revista Psicologia e Sociedade. Porto Alegre, v 16, n. 1, p. 15-22, jan/abr 2007a.

. Cartografias da invenção: pistas e políticas de um método de pesquisa. Seminário oral. PPG PSI/UFRGS. Março de 2007b. 

. O método da cartografia e os quatro níveis da pesquisa-intervenção. In L. R. CASTRO, L. R.; BESSET, V. L. (Orgs.), Pesquisa-intervenção na infância e juventude.). Rio de Janeiro: Trarepa/FAPERJ, 2008. p. 465-489.

LANCETTI, A. Síntese metodológica. In: . (Org) SaúdeLoucura 7: saúde mental e saúde da família. 2 ed. São Paulo: Hucitec, 2002. p. 115-120.

. A amizade e o acompanhamento terapêutico. In: SANTOS, R.G. (Org.). Textos, texturas e tessituras no acompanhamento terapêutico. Equipe de Acompanhantes Terapêuticos do Instituto A Casa. São Paulo: Hucitec, 2006a. p. 21-26.

. Clínica peripatética. São Paulo: Hucitec, 2006b.

LIMA, N.T. O Brasil e a Organização Pan-Americana da Saúde: Uma história em três dimensões. In: FILKELMAN, Jacobo. (Org). Caminhos da Saúde Pública no Brasil. Rio de Janeiro: Editora da Fiocruz, 2002.

MATTOS, R.A. Os Sentidos da Integralidade: algumas reflexões acerca de valores que merecem ser defendidos. In: PINHEIRO, R.; MATTOS, R.A. (Org). Os sentidos da integralidade na atenção e no cuidado à saúde. Rio de Janeiro: UERJ-IMS, 2001. p. 39-63.

MERHY, E.E. Engravidando palavras: o caso da integralidade. In: PINHEIRO, R.; MATTOS, R.A. (Org). Construção social da demanda: direito à saúde, trabalho em equipe, participação e espaços públicos. Rio de Janeiro: UERJ-IMS, 2005. p. 195-206.

GUILHERME NETO, J. et al. Possíveis caminhos de atenção à Saúde (Mental): A itinerância compondo a rede de desinstitucionalização. Saúde em Porto Alegre, Porto Alegre, v. 1, n. 1, 2004.

PALOMBINI, A.L. (Org.). Acompanhamento terapêutico na rede pública: a clínica em movimento. Porto Alegre: EdUFRGS, 2004.

Acompanhamento terapêutico: dispositivo clínico-político. Psyche, São Paulo, v. 10, n.18, p.115-127, set. 2006.

Vertigens de uma psicanálise a céu aberto: a cidade. Contribuições do acompanhamento terapêutico à clínica da reforma psiquiátrica. Tese (Doutorado em Saúde Coletiva) - Instituto de Medicina Social, Universidade do Estado do Rio de Janeiro. Rio de Janeiro, 2007.

PEREIRA NETO, A.F.. Os médicos e as enfermeiras visitadoras. In: Palavras, gestos e intenções. Os interesses profissionais da elite médica. Congresso Nacional dos Práticos (1922). 1997. 332 p. Tese (Doutorado em Saúde Coletiva) - Instituto de Medicina Social, Universidade do Estado do Rio de Janeiro, Rio de Janeiro. p.145-157.

PETUCO, D.R.S.; MEDEIROS, R.G. Redução de danos: dispositivo da reforma? Trabalho completo. In: Simpósio Temático: Acompanhamento Terapêutico como dispositivo da Reforma Psiquiátrica. III Congresso Internacional - IV Congresso Ibero-americano - II Congresso Brasileiro de Acompanhamento Terapêutico. Multiversas cidades, andanças caleidoscópicas, 
tessitura de redes. Porto Alegre, 2008. Disponível em: http://www.abordabrasil.org/biblioteca/

Producao\%20Academica/Medeiros\%20e\%20Petuco.pdf Acesso em: 15 fev. 2009.

PINHEIRO, R. et al. Demanda em saúde e direito à saúde: liberdade ou necessidade? Algumas considerações sobre os nexos constituintes das práticas de integralidade. In: PINHEIRO, R.; MATTOS, R.A. (Org). Construção social da demanda: direito à saúde, trabalho em equipe, participação e espaços públicos. Rio de Janeiro: UERJ-IMS, 2005. p. 11-29.

PELliCCIOLI, E. (Org.). Cadernos de AT: uma clínica itinerante. Porto Alegre: Grupo de Acompanhamento Terapêutico Circulação, 1987.

RISI JUNIOR, J.B.; NOGUEIRA, R.P. As condiçōes de saúde no Brasil. In: FILKELMAN, J. (Org.). Caminhos da Saúde Pública no Brasil. Rio de Janeiro: Editora da Fiocruz, 2002.

ROLNIK, S. Cartografia sentimental: transformações contemporâneas do desejo. Porto Alegre: EdUFRGS, 2006.

. Clínica Nômade. In: EQUIPE de Acompanhantes Terapêuticos do hospital dia A Casa (Org.). Crise e cidade. acompanhamento terapêutico. São Paulo: Educ, 1997. p. 83-97. ROTELLI, F.; LEONARDIS, O.; MAURI, D. Desinstitucionalização, uma outra via: a reforma psiquiátrica italiana no contexto da Europa Ocidental e dos "países avançados”. In: NICÁCIO, M.F.S. (Org). Desinstitucionalização. São Paulo: Hucitec, 1992. p. 17-59.

SOUZA, T.P. Redução de danos no Brasil: a clínica e a política em movimento. Dissertação (Mestrado em Psicologia) - Programa de Pós-Graduação em Psicologia. Departamento de Psicologia. Universidade Federal Fluminense. Niterói, 2007.

SILVA, R.V.B. et al. Do elo ao laço: o agente comunitário na construção da integralidade em saúde. In: PINHEIRO, R.; MATTOS, R.A. (Org.). Cuidado: as fronteiras da integralidade. Rio de Janeiro: Cepesc, 2005. p. 75-90.

SILVA, A.S.T. A emergência do acompanhamento terapêutico: o processo de constituição de uma clínica. Dissertação (Mestrado em Psicologia) - Programa de Pós-Graduação em Psicologia Social e Institucional, Instituto de Psicologia, Universidade Federal do Rio Grande do Sul, Porto Alegre, 2005.

TENÓRIO, F. A psicanálise e a clínica da reforma psiquiátrica. Rio de Janeiro: Rios Ambiciosos, 2001.

\section{Nota}

${ }^{1}$ Lancetti (2006b), ao falar sobre a clínica peripatética, afirmou que os conceitos de cartografia, assim como o de agenciamento, têm uma riqueza muito grande a ser explorada pelas práticas clínicas. No presente artigo tentamos desenvolver esses conceitos. 


\section{A study on itinerancy as a strategy of care within public health policies in Brazil}

This paper aims to problematize the itinerancy as a way to operationalize care in the territory. With the creation of the Unified Health System, the notion of territory has become an organizing principle of work processes in primary health care and mental health policies. In the delicate field of coordination between these policies, itinerant practices now have a strategic importance in the deinstitutionalization of practices and construction of integral care. We take the deinstitutionalization and the integrality as conceptual operators that make the difference that Psychiatric and Health reforms want to print in the care practices. Warned that by joining in a posture of active search in the life territory of users, the itinerant practices fall in a field of tensions, which can both be called to work as a part of the State apparatus to population control, as in a strategic place for the construction of a contextualized care to users" way of life. We believe that it is possible to resist the social control mandate and build an ethics of care with itinerancy to explore the political power of the movement and transform the users' territory in a laboratory for the invention of life.

Key words: mental health; primary health care; territory; deinstitutionalization. 